City University of New York (CUNY) CUNY Academic Works

2017

\title{
On the Overlap of Vital Exhaustion and Depression
}

\author{
Bianchi Renzo \\ Université de Neuchâtel \\ Irvin Sam Schonfeld \\ CUNY Graduate Center
}

Eric Laurent

Université Bourgogne - Franche-Comté

\section{How does access to this work benefit you? Let us know!}

More information about this work at: https://academicworks.cuny.edu/gc_pubs/460

Discover additional works at: https://academicworks.cuny.edu

This work is made publicly available by the City University of New York (CUNY).

Contact: AcademicWorks@cuny.edu 


\section{On the overlap of vital exhaustion and depression}

A R T I C L E I N F O

\author{
Keywords: \\ Burnout \\ Depression \\ Measurement \\ Methodology \\ Psychometrics \\ Vital exhaustion
}

\begin{abstract}
"A potential hazard is that using different terms for a similar phenomenon produces confusion within a research community, leading to miscommunication and misunderstandings that can impede theory development. This concern is compounded in that the advancement of existing theory relies on future researchers' ability to build on previous work."
\end{abstract}

Cole et al. (2012, p. 1573).

Vital exhaustion (VE) has been defined as a syndrome combining pervasive fatigue, irritability, and demoralization and resulting from a lack of control over important aspects of one's life $[1,2]$. Whether VE is anything other than an unnecessary variation on the theme of depression remains an unresolved question [3]. As an illustration, in an often-cited study, van Diest and Appels [4] found that men categorized as exhausted:

- globally reported more depressive symptoms (e.g., "fatigability" and "sleep disturbance") than men categorized as nonexhausted;

- but seldom complained about depressed mood-a core manifestation of depression [5].

These findings led these authors to suggest that VE is distinct from depression. The study, however, had a number of limitations that prevented clear conclusions from being drawn:

- VE was arbitrarily categorized following a tercile-based split;

- the study samples were small $(n s \leq 12)$;

- and only male participants were examined.

Moreover, van Diest and Appels [4] did not consider that, especially in men, feelings such as sadness (a component of depressed mood) can be denied at first and only become apparent when in-depth clinical interviews are conducted [5]; such interviews were not carried out in the study. The problem of the distinctiveness of VE with respect to depression may not be resolvable without an integrative reflection on the symptom picture and measurement of VE.

While the debate remains open, the view that VE is distinct from depression has prevailed in the literature-VE continues to be studied as a separate entity. In this viewpoint article, we propose a critical analysis of the VE construct, pointing to overlooked similarities between VE and depression. We argue that:

- the basic symptoms of VE are depressive in nature;

- and the main measure of VE, the Maastricht Questionnaire [2] (Appendix A), is in fact a measure of depression.

On these grounds, we call for a reconsideration of the view that VE is distinct from depression.

\section{Comparative symptomatology of VE and depression}

The first component of VE, pervasive fatigue, is also one of the nine diagnostic criteria for major depressive disorder (MDD) [5]. Pervasive fatigue is additionally involved in the diagnosis of persistent depressive disorder (dysthymia), a less acute form of depression [5]. Importantly, the claim that the primacy of pervasive fatigue distinguishes VE from depression [1] overlooks the fact that pervasive fatigue can be a central symptom in many forms of depression, for example, depression with atypical features. ${ }^{1}$

Although not a diagnostic criterion for MDD in the latest edition of the Diagnostic and Statistical Manual of Mental Disorders (DSM5 ), irritability, the second component of VE, is highly prevalent among depressed individuals. As mentioned in the DSM-5, "many individuals report or exhibit increased irritability (e.g., persistent anger, a tendency to respond to events with angry outbursts or blaming others, an exaggerated sense of frustration over minor matters)" when experiencing $\operatorname{MDD}$ ([5], p. 163). Judd et al. [6] even found that the presence of irritability/anger during major depressive episodes was a clinical marker of a more severe, chronic, and complex depressive illness.

Demoralization, the third and last component of VE, is characterized by feelings of impotence, isolation, and despair and is associated with damaged self-esteem [7]. As made explicit

\footnotetext{
${ }^{1}$ The term atypical "does not connote an uncommon or unusual clinical presentation” ([5], p. 186).
} 
by Frank [7], depressive symptoms are "direct expressions of demoralization" (p. 271). Feelings of impotence, isolation, and despair are usual constituents of depressed mood. This observation further calls into question van Diest and Appels's [4] conclusion that depressed mood plays a minor role in VE.

The three defining features of VE overlap with long-documented manifestations of depressive conditions. The symptomatologybased arguments that have been put forward to justify the claim that $\mathrm{VE}$ is a unique syndrome do not stand up to close scrutiny.

\section{Assessing the assessor}

The overlap of VE with depression is further detectable in the Maastricht Questionnaire [2]-the instrument of reference for the assessment of VE. As can be seen from Appendix A, the items of the Maastricht Questionnaire refer to pervasive fatigue and loss of energy (e.g., items 1 and 4), sleep disturbance (e.g., item 3), cognitive impairment (e.g., item 21), death wishes (item 16), feelings of helplessness, apathy, and hopelessness (e.g., items 6, 8, and 10), irritability (e.g., item 12), loss of libido (item 9), and lowered mood (e.g., items 14 and 18). Most of these symptoms correspond to established diagnostic criteria for depression; all of them pertain to depressive clinical pictures [5].

Consistent with these observations, Wojciechowski et al. [8] found strong and virtually identical correlations between two measures of depression (the Zung Self-Rating Depression Scale and the depression subscale of the SCL-90) and the Maastricht Questionnaire at four different measurement points. Based on principal component analyses, Vroege et al. [9] did not find evidence that the symptoms of $\mathrm{VE}$, as assessed with the Maastricht Questionnaire, exceeded the scope of depressive manifestations, as assessed by the Beck Depression Inventory. VE specifically overlapped with the somatic-affective dimension of depression. Frestad and Prescott [3] conducted a systematic review and metaanalysis of 16 studies dedicated to the impact of VE on coronary heart disease (CHD). Remarkably, in the only included study in which depression (assessed with the Center for Epidemiological Studies Depression scale) was analyzed as a potential confounder, VE no longer predicted CHD once depressive symptoms were controlled.

All in all, there is converging evidence that VE is integral part of the depressive spectrum. Some investigators, however, may suppose that VE represents a specific subtype of depression. Whether a new, VE-inspired subtype of depression is needed requires further investigation. This being noted, depression with atypical features, an existing subtype of depression, may already overlap VE. Pervasive fatigue (e.g., loss of energy, hypersomnia, leaden paralysis) lies at the heart of depression with atypical features [5]. In addition, interpersonal rejection sensitivity, a diagnostic criterion for depression with atypical features, is an aspect of the demoralization component of VE [7].

\section{Conclusion}

Our reexamination of the symptoms and main measure of VE suggests that the overlap of VE with depression has been problematically underestimated due to inconsistent comparisons and blindness to definitional similarities. In our view, the case of VE is emblematic of a trend toward construct proliferation [10]. Many "new" constructs are introduced in the literature precipitously, with insufficient examination of their added value, and based on "linguistic contortions" and anecdotal evidence rather than robust empirical findings and sound theorizing. Such constructs are often "distinguished" from existing ones on the basis of specious arguments and missing-the-point conclusions. This is for instance the case when Appels and Mulder [1] overlook the fact that depressed mood and lowered self-esteem cannot be invoked to distinguish depression from VE because depressed mood and lowered self-esteem are constituents of demoralization, a component of VE. We plead for a greater respect of the principle of parsimony, in the interest of theoretical clarity and effective transdisciplinary communication.

To close this article, we note that VE has often been equated with burnout [3]. Interestingly, burnout has been found to overlap with depression. These findings provide indirect support for the view that VE is a depressive condition. Whether other exhaustion syndromes such as neurasthenia-originally considered to be part of "melancholia"-and compassion fatigue-a recently described condition with fuzzy definitional contours-would not be better conceived of as depressive syndromes should be clarified.

\section{Disclosure of interest}

The authors declare that they have no competing interest.

\section{Appendix A. The Maastricht Questionnaire (21-item version) [2]}

Medical research is constantly trying to track down the causes of disease. You would help this research by answering the following questions about how you feel lately. Please mark the answers that are true for you. If you don't know or cannot decide circle the '?'. There are no 'right' or 'wrong' answers.

\begin{tabular}{|c|c|c|c|c|}
\hline 1 & Do you often feel tired? & Yes & ? & No \\
\hline 2 & Do you often have trouble falling asleep? & Yes & ? & No \\
\hline 3 & Do you wake up repeatedly during the night? & Yes & ? & No \\
\hline 4 & Do you feel weak all over? & Yes & ? & No \\
\hline 5 & $\begin{array}{l}\text { Do you have the feeling that you haven't } \\
\text { been accomplishing much lately? }\end{array}$ & Yes & ? & No \\
\hline 6 & $\begin{array}{l}\text { Do you have the feeling that you can't cope } \\
\text { with everyday problems as well as you used to? }\end{array}$ & Yes & ? & No \\
\hline 7 & Do you believe that you have come to a 'dead end'? & Yes & ? & No \\
\hline 8 & Do you lately feel more listless than before? & Yes & ? & No \\
\hline 9 & I enjoy sex as much as ever & Yes & ? & No \\
\hline 10 & $\begin{array}{l}\text { Have you experienced a feeling of hopelessness } \\
\text { recently? }\end{array}$ & Yes & ? & No \\
\hline 11 & $\begin{array}{l}\text { Does it take more time to grasp a difficult } \\
\text { problem than it did a year ago? }\end{array}$ & Yes & ? & No \\
\hline 12 & $\begin{array}{l}\text { Do little things irritate you more lately } \\
\text { than they used to? }\end{array}$ & Yes & ? & No \\
\hline 13 & Do you feel you want to give up trying? & Yes & ? & No \\
\hline 14 & I feel fine & Yes & ? & No \\
\hline 15 & $\begin{array}{l}\text { Do you sometimes feel that your body is like a } \\
\text { battery that is losing its power? }\end{array}$ & Yes & ? & No \\
\hline 16 & Would you want to be dead at times? & Yes & $?$ & No \\
\hline 17 & $\begin{array}{l}\text { Do you have the feeling these days that you just } \\
\text { don't have what it takes anymore? }\end{array}$ & Yes & ? & No \\
\hline 18 & Do you feel dejected? & Yes & ? & No \\
\hline 19 & Do you feel like crying sometimes? & Yes & ? & No \\
\hline 20 & $\begin{array}{l}\text { Do you ever wake up with a feeling of } \\
\text { exhaustion and fatigue? }\end{array}$ & Yes & ? & No \\
\hline 21 & $\begin{array}{l}\text { Do you have increasing difficulty in concentrating } \\
\text { on a single subject for long? }\end{array}$ & Yes & ? & No \\
\hline
\end{tabular}

\section{References}

[1] Appels A, Mulder P. Fatigue and heart disease. The association between 'vital exhaustion' and past, present and future coronary heart disease. J Psychosom Res 1989:33(6):727-38.

[2] Appels A, Höppener P, Mulder P. A questionnaire to assess premonitory symptoms of myocardial infarction. Int J Cardiol 1987;17(1):15-24.

[3] Frestad D, Prescott E. Vital exhaustion and coronary heart disease risk: a systematic review and meta-analysis. Psychosom Med 2017;79(3):260-72.

[4] van Diest R, Appels A. Vital exhaustion and depression: a conceptual study. J Psychosom Res 1991;35(4-5):535-44.

[5] American Psychiatric Association. Diagnostic and statistical manual of mental disorders, 5th ed., Washington, DC: American Psychiatric Publishing; 2013.

[6] Judd LL, Schettler PJ, Coryell W, Akiskal HS, Fiedorowicz JG. Overt irritability/ anger in unipolar major depressive episodes: past and current characteristics 
and implications for long-term course. JAMA Psychiatry 2013;70(11): 1171-80.

[7] Frank JD. Psychotherapy: the restoration of morale. Am J Psychiatry $1974 ; 131(3): 271-4$

[8] Wojciechowski FL, Strik JJMH, Falger P, Lousberg R, Honig A. The relationship between depressive and vital exhaustion symptomatology post-myocardial infarction. Acta Psychiatr Scand 2000;102(5):359-65.

[9] Vroege EM, Zuidersma M, de Jonge P. Vital exhaustion and somatic depression: the same underlying construct in patients with myocardial infarction? Psychosom Med 2012;74(5):446-51.

[10] Cole MS, Walter F, Bedeian AG, O'Boyle EH. Job burnout and employee engagement: a meta-analytic examination of construct proliferation. J Manag 2012;38(5):1550-81.

R. Bianchi*

Institute of Work and Organizational Psychology, University of Neuchâtel, Neuchâtel, NE, Switzerland

I.S. Schonfeld

Department of Psychology, The City College of the City University of New York, New York City, NY, USA
E. Laurent Laboratory of Psychology (EA 3188), Bourgogne Franche-Comté University, Besançon, France

${ }^{*}$ Corresponding author at: Institute of Work and Organizational Psychology, University of Neuchâtel, Émile-Argand 11, 2000 Neuchâtel, NE, Switzerland E-mail address: renzo.bianchi@unine.ch (R. Bianchi)

Received 30 March 2017 Received in revised form 30 March 2017

Accepted 10 April 2017 Available online 28 April 2017 